\title{
Glucose absorption from starch hydrolysates in the human jejunum
}

\author{
B J M JONES, B E BROWN, J S LORAN, D EDGERTON, J F KENNEDY, \\ J A STEAD, AND D B A SILK
}

From the Departments of Gastroenterology and Clinical Chemistry. The Central Middlesex Hospital, London, The Department of Chemistry, University of Birmingham, and Roussel Laboratories Limited, Swindon, Wiltshire

SUMmaRY The intestinal absorption and mucosal hydrolysis of a partial and a complete $\alpha$-amylase hydrolysate of corn starch, simulating the normal intermediary and end products of luminal starch digestion, was studied using an in vivo steady state jejunal perfusion technique in normal human subjects. Alpha-amylase was excluded from the test segment by proximal balloon occlusion. Products of hydrolysis during intestinal perfusion were identified using gel permeation chromatography. Three isocaloric, isotonic sugar saline solutions containing $140 \mathrm{mM}$ glucose, 70 $\mathrm{mM}$ maltose and the partial amylase hydrolysate of starch $(51.5 \pm 1.4 \%$ of glucose content comprising glucose polymers of more than 10 glucose units) were perfused in the first study. Net glucose absorption during perfusion of the partial hydrolysate and free glucose was similar, but significantly faster from maltose $(\mathrm{p}<0.05)$. Hydrolysis of the polymer fraction containing more than 10 glucose units was significantly slower $(29.5 \pm 2.0 \%$ of infused load) than the lower molecular weight fraction $(56 \cdot 4 \pm 3 \cdot 8 \%, \mathrm{p}<0.001)$. As net glucose absorption from the partial hydrolysate was similar to that from glucose, despite the slow hydrolysis of the higher molecular weight fraction, it seemed likely that oligosaccharides in the more rapidly hydrolysed lower molecular weight fractions were exerting a kinetic advantage on glucose absorption. This was confirmed in a second study, where glucose absorption from a complete amylase hydrolysate consisting predominantly of maltose, maltotriose and $\alpha$-limit dextrins, occurred significantly faster $(81.8 \pm 4.8 \mathrm{mmol} / \mathrm{h} / 25 \mathrm{~cm})$ than from isocaloric free glucose $(55.8 \pm 4.9 \mathrm{mmol} / \mathrm{h} / 25 \mathrm{~cm}$, $\mathrm{p}<0 \cdot 001)$. Chromatograms of intestinal aspirates suggested that $(1 \rightarrow 4)$, but not $(1 \rightarrow 6)$ linked oligosaccharides liberated during luminal and brush-border hydrolysis of dietary starch conferred a kinetic advantage on glucose absorption.

The digestion of dietary starch has a luminal phase involving salivary and pancreatic $\alpha$-amylase and a subsequent membrane phase involving mucosal brush-border oligosaccharide hydrolases. As a result, the starches are completely hydrolysed to the monosaccharide D-glucose, the only form in which nutritionally significant absorption occurs. ${ }^{1}$

There is still a good deal of speculation concerning the interrelationships between the brush-border hydrolysis of the products of luminal starch hydrolysis and glucose transport. ${ }^{2}$ Research in this area in man has largely been restricted to the

Address for correspondence: Dr B J M Jones, London Hospital, Whitechapel, London E1 1BB.

Received for publication 11 March 1983 investigation of maltose assimilation. Initial studies showing similar rates of absorption from glucose and maltose merely suggested that brush-border maltose hydrolysis was not a rate limiting step in absorption. ${ }^{34}$ Glucose absorption has been shown more recently, however, to occur faster from maltose than from glucose, indicating that brush-border maltose hydrolysis confers a kinetic advantage on glucose absorption. ${ }^{5-7}$

The disaccharide maltose is only one of numerous intermediate and end products of luminal starch hydrolysis comprising $(1 \rightarrow 4)$ and $(1 \rightarrow 6)$ linked $\alpha$-D-gluco-oligosaccharides, $\alpha$-limit dextrins and the $(1 \rightarrow 4)$ linked maltotetraose and maltotriose. ${ }^{1}$ The present study was therefore undertaken to determine whether any of these other hydrolysis products 
also confers a kinetic advantage on glucose uptake.

An in vivo jejunal perfusion technique has been used in normal human subjects to study these aspects of carbohydrate absorption. Investigations comprised measurements of the rates of hydrolysis and of subsequent glucose transport during steady state perfusion of two $\alpha$-amylase hydrolysates of corn starch, one simulating the intermediary luminal hydrolysis products and the other the complete end products of luminal starch hydrolysis.

\section{Methods}

\section{MATERIALS AND SUBJECTS}

A partial amylase hydrolysate of starch simulating the intermediary products of luminal starch hydrolysis was produced by the partial hydrolysis (amylolysis) of corn starch by bacterial $\alpha$-amylases and consisted of a single batch of a $(1 \rightarrow 4),(1 \rightarrow 6)$ glycosidically linked $\alpha$-D-glucose polymer mixture with a minority of $(1 \rightarrow 6)$ branch points. This preparation is freely available in the United Kingdom and is marketed as Caloreen (Roussel Laboratories Limited, Wembley, England).

A complete $\alpha$-amylase hydrolysate of starch, simulating the end products of luminal starch digestion was prepared in batches by adding 5000 units of $\alpha$-amylase (1,4- $\alpha$-D-glucose glucanohydrolase (EC 3.2.1.1. porcine pancreas, Boehringer Mannheim) to $24 \cdot 2 \mathrm{~g}$ Caloreen and $7 \mathrm{~g}$ sodium chloride dissolved in one litre distilled water. The $\mathrm{pH}$ was adjusted to 7.0 by the addition of $0 \cdot 1 \mathrm{M}$ sodium hydroxide and the solution incubated at $37^{\circ} \mathrm{C}$ for two hours after which no further rise in osmolality could be detected indicating that the reaction had proceeded to completion.

Glucose Analar ${ }^{\circledR}$, maltose and sodium chloride Analar ${ }^{\circledR}$ were purchased from BDH Chemicals Limited, England, and ${ }^{14} \mathrm{C}$-labelled polyethylene glycol 4000 (PEG) from the Radiochemical Centre, Amersham, England.

\section{GEL PERMEATION CHROMATOGRAPHY}

The composition of the partial and exhaustive $\alpha$-amylase hydrolysates of starch used in the perfusion studies were determined using a system of gel permeation chromatography (GPC) modified from that of John et al. ${ }^{8}$ This system separated and classified components on the basis of molecular size (J F Kennedy and J Singh, unpublished data). The same technique was also used to identify the hydrolysis products liberated during the course of the perfusion experiment.

A water jacketed glass column $(2.2 \mathrm{~m}$ height $\times 19$ $\mathrm{mm}$ id) was packed at $20^{\circ} \mathrm{C}$ with an aqueous slurry of BIO-GEL P2, 200-400 mesh (Bio-Rad Labora- tories), preswollen in water and vacuum deaerated under water at $20^{\circ} \mathrm{C}$ to remove entrapped air. When almost fully packed, an Altex adjustable plunger assembly was fitted to take up any dead volume at the top of the column. The jacket temperature was slowly raised to $65^{\circ} \mathrm{C}$ while the column was eluted with deaerated water, using a Technicon positive displacement pump at a flow rate of about $30 \mathrm{ml} / \mathrm{h}$.

Once the column was fully equilibrated (after about 48 hours) the elution with water was continued at $1 \mathrm{ml}$ aliquots of suitably diluted samples (1-1000 $\mu \mathrm{g}$ of each component) were introduced into the elution stream by means of a sample loop valve. Recrystallised orcinol dissolved in concentrated sulphuric acid $1.5 \mathrm{~g} / \mathrm{l}$ was mixed with eluant from the column in a Technicon Auto Analyser. The reagent (pumping rate $24 \mathrm{ml} / \mathrm{h}$ ) was mixed with eluate (sampling rate $12 \mathrm{ml} / \mathrm{h}$ ) in the assay manifold and passed through a heating coil maintained at $95^{\circ} \mathrm{C}$ (residence time 15 minutes). The resultant colour was determined spectrophotometrically in a Technicon AA2 Colorimeter fitted with $420 \mathrm{~nm}$ absorbance filters.

The molecular sizes of unknown components of the sample were identified by their elution position compared with a chart for standards including isomaltose and isomaltotriose run under the same conditions, and were quantitated by estimation of the area under the peak. Comparative quantitation was achieved by expression of the area under each peak as a percentage of the total area under all peaks. All data are based on calibration of the column with a standard malto-oligosaccharide mixture and D-glucose. Elution positions of individual components have been shown to be absolutely critical with respect to each other, elution positions of other disaccharides and monosaccharides being identifiably different from those of maltose, isomaltose, and glucose. Carbohydrate recovery has been independently shown to be $100 \%$ complete. Other independent assays have confirmed that the final colorimetric stage of the chromatography was independent of chain length of oligosaccharide, a decasaccharide giving five times the molar response of a disaccharide.

\section{PERFUSION TECHNIQUE}

Intestinal perfusion experiments were performed in 12 normal volunteers (nine men, three women, ages 21-23 years), some of whom took part in both phases of the study on different days. After an overnight fast, each subject was intubated on the morning of the experiment with a double lumen perfusion tube incorporating a proximal occlusive balloon. The tube was allowed to pass until the infusion port was distal to the duodenojejunal 
flexure. The final position of the tube was checked radiologically, so that the $25 \mathrm{~cm}$ perfusion segment lay in the proximal jejunum..$^{9-11}$

The perfusion solutions were pumped at 20 $\mathrm{ml} / \mathrm{min}$ through the infusion port by a peristaltic pump (H R Flow Inducer, Watson-Marlow Limited, Marlow, Bucks, England) from bottles maintained at $37^{\circ} \mathrm{C}$ in a water bath. After an equilibration period of 30 minutes three 10 minute samples were collected from the distal collecting port by syphonage. The samples were collected into a container kept chilled with crushed ice.

The nature of the study was explained fully to each subject and ethical approval was obtained from the Ethical Committees at the Middlesex Hospital Medical School and the Central Middlesex Hospital, London.

\section{EXPERIMENTAL DESIGN}

(1) Partial amylase hydrolysate of starch

Jejunal perfusion experiments were performed to investigate the in vivo (brush-border) hydrolysis of the partial amylase hydrolysate of starch in the absence of luminal $\alpha$-amylase activity and to compare the rates of glucose absorption from this preparation with the rates of glucose absorption from equivalent maltose and free glucose solutions. Each subject was perfused with three sugar-saline solutions in random order on the same day. Solutions contained either (1) $140 \mathrm{mM}$ glucose, (2) $70 \mathrm{mM}$ maltose, or (3) the partial amylase hydrolysate of starch. All solutions yielded $140 . \mathrm{mmol} / \mathrm{l}$ free glucose after complete hydrolysis and to render them isotonic with plasma, 73,110 and $138 \mathrm{mmol} / \mathrm{l}$ $\mathrm{NaCl}$ were added respectively.

(2) Complete amylase hydrolysate of starch Jejunal perfusion experiments were performed to investigate the in vivo intestinal hydrolysis of the complete amylase hydrolysate of starch and to compare the rate of glucose absorption from this preparation with that from the partial amylase hydrolysate and an equivalent free glucose solution.

Thus a further group of subjects was perfused, each subject receiving the three sugar-saline solutions in random order on the same day. Solutions contained either (1) $140 \mathrm{mmol} / \mathrm{l}$ glucose, (2) the partial amylase hydrolysate of starch, or (3) the complete amylase hydrolysate of starch. Again all three solutions yielded $140 \mathrm{mmol} / \mathrm{l}$ free glucose after complete hydrolysis and contained $1 \mu \mathrm{Ci}^{14} \mathrm{C}$ PEG $4000 / 1$ as a non-absorbable marker. ${ }^{12}$

ANALYTICAL TECHNIQUE

Luminal amylase activity

Intestinal contents aspirated during intestinal per- fusion of the partial $\alpha$-amylase hydrolysate of starch were assayed for $\alpha$-amylase activity. The method used (Phadebas Amylase Test Kit, Pharmacia, Mannheim) described in detail elsewhere ${ }^{13}$ was capable of detecting $\alpha$-amylase activity in undiluted samples down to an activity of $37 \mathrm{IU} / \mathrm{l}$. All data reported in this paper pertaining to the intestinal assimilation of the partial amylase hydrolysate of starch were derived from the assay of intestinal aspirates found to be free of detectable $\alpha$-amylase activity using this method.

\section{Free glucose estimation}

Free glucose content of the test solutions and of the jejunal aspirates was assayed by the Hexokinase UV method using the Boehringer Hexokinase Kit (Boehringer Mannheim). Ultraviolet absorption of the reaction mixture was measured at $340 \mathrm{~nm}$ with an UV Spectrophotometer (Pye-Unicam Limited, Cambridge, England).

\section{Quantitative enzymatic hydrolysis of maltose} and the starch hydrolysates

Total glucose content of test solutions containing maltose, the two starch hydrolysates and their respective aspirates was assayed by the Hexokinase method after complete hydrolysis with amyloglucosidase (1,4- $\alpha$-D-glucan glucohydrolase EC 3.2.1.1. Aspergillus niger, Boehringer Mannheim).

A $0.5 \mathrm{ml}$ solution to be assayed (dilution 1 in 15) was added to $1 \mathrm{ml}$ acetate buffer at $\mathrm{pH} 2.8,0.06 \mathrm{ml}$ distilled water and $0.04 \mathrm{ml}$ amyloglucosidase (10 $\mathrm{mg} / \mathrm{ml}$ ) and incubated for one hour at $37^{\circ} \mathrm{C}$ after which $0.4 \mathrm{ml}$ of 0.3 Tris was added. Liberated glucose was then assayed by the Hexokinase method as above.

The original method described for glycogen by Keppler and Decker ${ }^{14}$ allowed two hours for complete hydrolysis to free glucose at a $\mathrm{pH}$ of 4.8 . We found this method required 72 hours for complete hydrolysis of the partial starch hydrolysate to free glucose and therefore modified this method for the present study as described above. Complete recovery of maltose and the partial starch hydrolysate was possible and the method was equally applicable to intestinal aspirates.

\section{${ }^{14} \mathrm{C}$ PEG}

One millilitre of test solution was added to $14 \mathrm{ml}$ of scintillation fluid (Triton $\times 100$; Toluene, 2:5; Diphenyloxazole (PPO), BDH Chemicals Limited, England), and the activity measured with a Packard Tri-Carb Liquid Scintillation Scanner 2425.

\section{Osmometry}

Osmolalities of the infused test solutions were 
measured by the depression of freezing point method using a cryoscopic osmometer (Advanced Osmometer AD3W, MSE Scientific Instruments, Crawley, W Sussex, England).

\section{CALCULATION OF RESULTS}

Absorption of glucose from free glucose, maltose, and the two starch hydrolysate solutions was calculated from the basic formula: ${ }^{15}$

$$
G_{n}=\left[G_{i}-\left(G_{a} \times \frac{P^{P E G}}{P E G_{a}}\right)\right] \times R
$$

where $G_{n}=$ net rate of glucose absorption (mmol/ $\mathrm{h} / 25 \mathrm{~cm}$ )

$\mathrm{G}_{\mathrm{i}}=$ total glucose content of the perfusion solution $(\mathrm{mmol} / \mathrm{l})$

$\mathrm{G}_{\mathrm{a}}=$ total glucose content of the jejunal aspirate $(\mathrm{mmol} / \mathrm{l})$

$\mathrm{PEG}_{\mathrm{i}}=$ PEG content of perfusion solution $(\mathrm{cpm} / \mathrm{ml})$

$\mathrm{PEG}_{\mathrm{a}}=\mathrm{PEG}$ content of jejunal aspirates $(\mathrm{cpm} /$ $\mathrm{ml}$ )

$R=$ rate of infusion $(1 / h)$.

The overall rate of hydrolysis of maltose and the two amylase hydrolysates of starch was calculated from the formula:

$$
H_{r}=G_{n}+F_{p}
$$

where $\mathrm{H}_{\mathrm{r}}=$ net hydrolysis rate (mmol glucose released $\mathrm{h} / 25 \mathrm{~cm}$ )

$\mathrm{G}_{\mathrm{n}}=$ net rate of glucose absorption (mmol/ $\mathrm{h} / 25 \mathrm{~cm}$ )

$\mathrm{FG}_{\mathrm{p}}=$ net rate of free glucose appearance in the jejunal lumen during substrate perfusion $(\mathrm{mmol} / \mathrm{h} / 25 \mathrm{~cm})$.

FG was calculated from the formula:

$$
F G_{p}=\left[\left(F G_{a} \frac{P E G_{i}}{P E G_{a}}\right)-F G_{i}\right] \times R
$$

where $\mathrm{FG}_{\mathrm{i}}=$ concentration of free glucose in infused solution $(\mathrm{mmol} / \mathrm{l})$

$\mathrm{FG}_{\mathrm{a}}=$ concentration of free glucose in jejunal aspirates $(\mathrm{mmol} / \mathrm{l})$

The extent of hydrolysis (luminal disappearance) of substrate (applicable to maltose, the two amylase hydrolysates of starch and their constituent fractions) was calculated as follows:

$$
\begin{aligned}
\mathrm{H}_{\mathrm{e}} & =\frac{\left\{\mathrm{S}_{\mathrm{i}}-\left[\mathrm{S}_{\mathrm{a}} \times\left(\mathrm{PEG}_{\mathrm{i}} / \mathrm{PEG}_{\mathrm{a}}\right)\right]\right\}}{\mathrm{S}_{\mathrm{i}} \times \mathrm{R}} \mathrm{R} \times 100 \\
& =\frac{\left\{\mathrm{S}_{\mathrm{i}}-\left[\mathrm{S}_{\mathrm{a}} \times\left(\mathrm{PEG}_{\mathrm{i}} / \mathrm{PEG}_{\mathrm{a}}\right)\right]\right\}}{\mathrm{S}_{\mathrm{i}}} \times 100
\end{aligned}
$$

where $\mathrm{H}_{\mathrm{e}}=$ extent of hydrolysis (luminal disappearance) of substrate expressed as a percentage of the infused load of that substrate $^{*}$

$\mathrm{S}_{\mathrm{i}}=$ infused substrate concentration*

$\mathrm{S}_{\mathrm{a}}=$ aspirate substrate concentration*

* Substrate concentration expressed in terms of glucose $(\mathrm{mmol} / \mathrm{l})$ liberated by complete hydrolysis of substrate to free glucose.

\section{STATISTICAL METHODS}

Differences in hydrolysis rates and glucose absorption rates have been assessed within subjects by the paired $t$ test. Means are expressed \pm SEM.

\section{Results}

A representative chromatogram of the infused partial amylase hydrolysate of starch with the glucose content of the individual fractions is shown in Fig. 1A. The chromatograms contained multiple peaks, representing oligosaccharides of different chain lengths. The chromatographic method did not permit good resolution of individual fractions with chain lengths greater than 10 glucose molecules, nor did the method allow quantitative assessment of the proportion of $(1 \rightarrow 4)$ to $(1 \rightarrow 6)$ bonded oligosaccharides in the partial amylase hydrolysate.

Free glucose $(\mathrm{G} 1)$ comprised $2.4 \pm 0.3 \%$ of the total glucose content, maltose (G2) $4 \cdot 1 \pm 0.2 \%$, maltotriose (G3) $7 \cdot 3 \pm 0.2 \%$ and tetrasaccharide (G4) $5 \cdot 1 \pm 0 \cdot 4 \%$. Fractions within the range G3-G10 comprising both $(1 \rightarrow 4)$ linked oligosaccharides and $(1 \rightarrow 6)$ linked dextrins made up $41.6 \pm 1 \cdot 3 \%$ of the total glucose content and those fractions containing more than 10 glucose molecules $(<\mathrm{G} 10)$, $51 \cdot 5 \pm 1 \cdot 4 \%$.

\section{HYDROLYSIS OF THE PARTIAL AMYLASE}

HYDROLYSATE OF STARCH IN VIVO

The chromatographic profile of the partial amylase hydrolysate aspirates is shown in Fig. 1B and can be compared with the profile of the infused material (Fig. 1A): Appropriate dilutions were loaded onto the column in order to obtain a satisfactory chromatographic response and thus direct quantitative comparison of individual peaks within one chromatogram with those of another is not possible without first correcting for water absorption and total glucose content as described under 'calculations'. Thus the > G10 fraction of the partial amylase hydrolysate was hydrolysed even in the absence of luminal amylase activity as defined by our assay (Table 1).

There was also an obvious diminution of the G3-G10 fractions and an increase in the free glucose peak (G1), the end product of oligosaccharide brush-border hydrolysis. Both the extent $(p<0 \cdot 001)$ 
Fig. 1 Partial amylase hydrolysate of starch. Typical tracing obtained by gel permeation chromatography of partial amylase hydrolysate of corn starch $(A)$ used in perfusion studies, and intestinal aspirates (B) obtained during jejunal perfusion in absence of luminal amylase. Each peak represents glucose content of various glucose polymer fractions containing: $G 1$, free glucose; G2, maltose; G3, maltotriose; $G 4$, maltotetraose; G10, glucose polymers with 10 glucose units; $>G 10$, glucose polymers of longer chain length than 10 glucose units. Shown below tracing $A$ is the glucose content of individual peaks, or groups of peaks, expressed as a percentage of total glucose content of hydrolysate. Values are mean $\pm S E M$ of 12 separate samples of the same batch of hydrolysate. In this Figure and Fig. 2 ordinates represent absorbance in the analytical system and the abscissae elution time from the column.
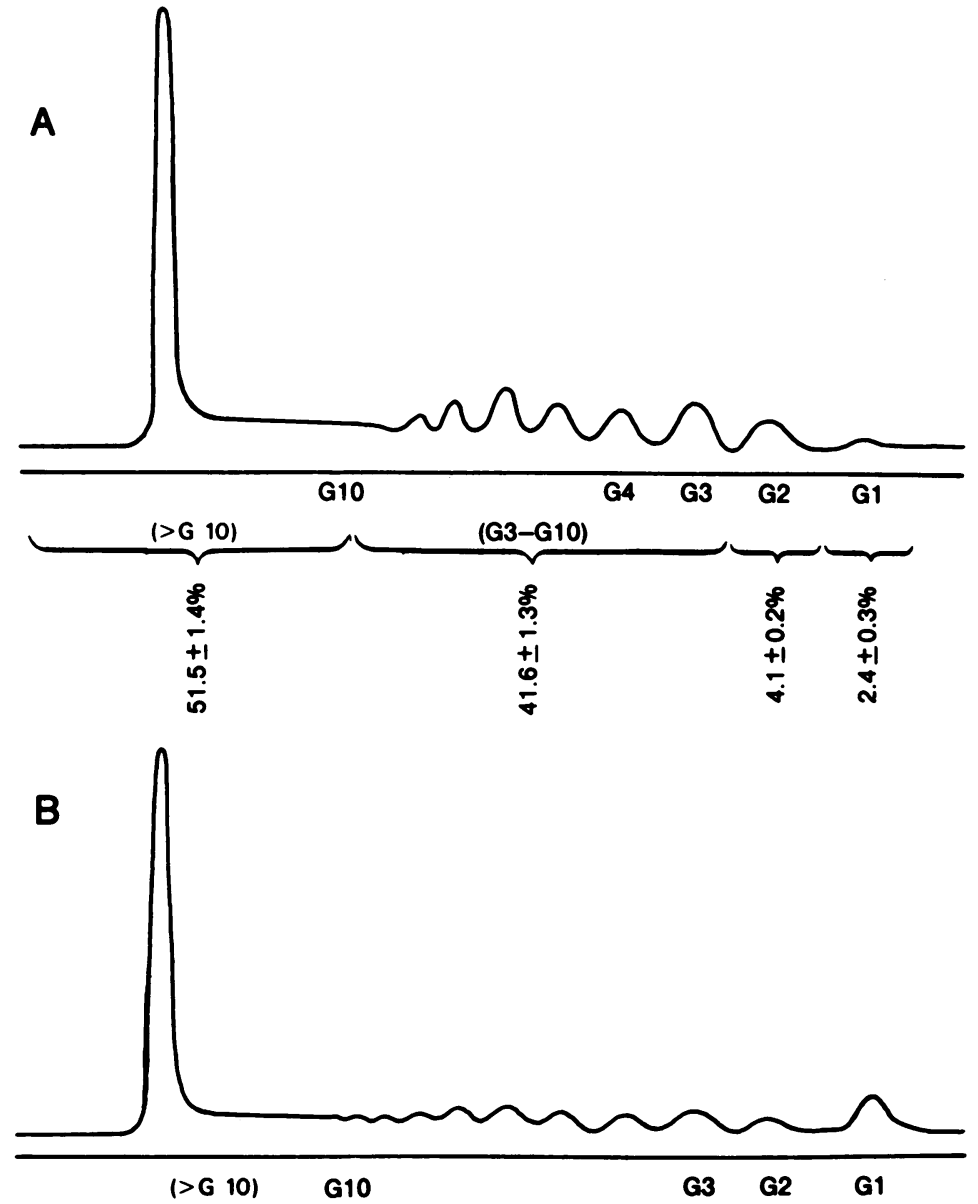

and the net rates $(p<0.02)$ of hydrolysis of the infused G3-G10 fraction were significantly greater than the extent and rate of hydrolysis of the higher molecular weight $(>\mathrm{G} 10)$ fraction (table 1). Net

Table 1 In vivo hydrolysis of the partial amylase hydrolysate of starch during human jejunal perfusion

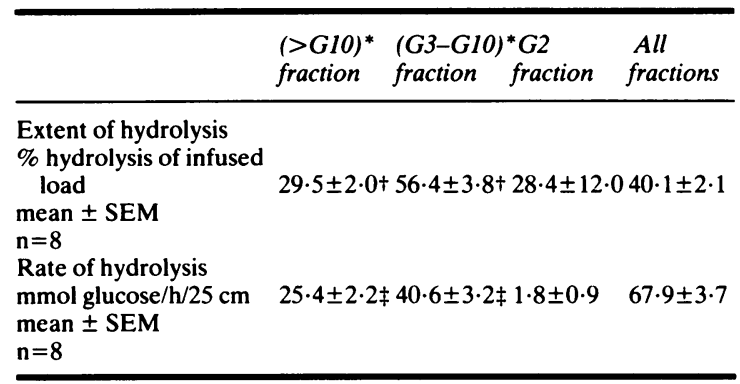

* Denotes chain length of individual glucose polymer fractions.

$+\mathrm{p}<0.001 \ddagger \mathrm{p}<0.02$. disappearance of maltose occurred during perfusion of this partial starch hydrolysate (Table 1 ) indicating that maltose hydrolysis was not rate limiting for assimilation of the partial starch hydrolysate. Overall hydrolysis of the partial hydrolysate $(67.9 \pm 3.7 \mathrm{mmol}$ glucose release $/ \mathrm{h} / 25 \mathrm{~cm})$ was greater than glucose absorption $(60 \cdot 1 \pm 3.8 \mathrm{mmol} /$ $\mathrm{h} / 25 \mathrm{~cm}$ ) despite the relatively slow hydrolysis of the $>$ G10 fraction $(25.4 \pm 2.2 \mathrm{mmol}$ glucose released/ $\mathrm{h} / 25 \mathrm{~cm})$.

GLUCOSE ABSORPTION (MMOL/H/25 CM \pm SEM)

FROM MALTOSE AND THE PARTIAL AMYLASE HYDROLYSATE OF STARCH (Table 2)

Net absorption of glucose from maltose $(84 \cdot 9 \pm 12 \cdot 2)$ was significantly faster than from the free glucose solution $(65 \cdot 8 \pm 12 \cdot 8, \mathrm{p}<0 \cdot 05, \mathrm{n}=6)$. Net absorption of glucose from the partial amylase hydrolysate of starch $(60 \cdot 8 \pm 3 \cdot 8, n=9)$ was similar to that from the free glucose solution. 
Table 2 Glucose absorption ( $\mathrm{mmol} / \mathrm{h} / 25 \mathrm{~cm} \pm S E M)$

\begin{tabular}{|c|c|c|}
\hline $\begin{array}{l}70 \mathrm{mM} \text { maltose } \\
\text { vs } 140 \mathrm{mM} \text { glucose }\end{array}$ & $\begin{array}{l}\text { Partial amylase } \\
\text { hydrolysate of starch } \\
\text { vs } 140 \mathrm{mM} \text { glucose }\end{array}$ & $\begin{array}{l}\text { Complete amylase } \\
\text { hydrolysate of starch } \\
\text { vs } 140 \mathrm{mM} \text { glucose }\end{array}$ \\
\hline $\begin{array}{l}84 \cdot 9 \pm 12 \cdot 2 \\
v s \\
65 \cdot 8 \pm 12 \cdot 8 \\
n=6 \\
p<() \cdot(05\end{array}$ & $\begin{array}{l}6() \cdot 8 \pm 3 \cdot 8 \\
\quad v s \\
53 \cdot 3 \pm 5 \cdot 6 \\
n=9 \\
\text { NS }\end{array}$ & $\begin{array}{l}\frac{81 \cdot 8 \pm 4 \cdot 8}{v s} \\
55 \cdot 8 \pm 4 \cdot 9 \\
n=6 \\
p<0 \cdot 001\end{array}$ \\
\hline
\end{tabular}

HYDROLYSIS OF THE COMPLETE AMYLASE HYDROLYSATE OF STARCH IN VIVO

The chromatographic profile of the complete amylase hydrolysate prepared in vitro is shown in Fig. 2A. Compared with the profile of the partial hydrolysate (Fig. 1A) there was a marked diminution in the peak area of the $>\mathrm{G} 10$ fraction with a preponderance of maltotriose (G3) and maltose (G2). A representative chromatographic profile of the intestinal aspirates obtained during perfusion of the complete amylase hydrolysate is shown in Fig. 2B. Compared with the profile of the infused material (Fig. 2A) there was little change in the peak area of the $>$ G10 fraction and only a small reduction in the G4-G10 fractions was evident by comparison with the large reduction in the $\mathrm{G} 3$ and G2 peaks. There was a marked rise in the free glucose peak (G1) and this rise was more marked than the equivalent rise noted during partial amylase hydrolysate infusion (Fig. 1B). Additional peaks appeared in the $\mathrm{G} 2$ and $\mathrm{G} 3$ fractions and were identified as representing the luminal accumulation of isomaltose and isomaltotriose containing $(1 \rightarrow 6)$ $\alpha$-D-glycoside linkages as determined by the well defined elution positions of these sugars based upon repeated calibration. These oligosaccharides are presumed to have arisen by brush-border hydrolysis of infused material.

Quantitatively, the complete $\alpha$-amylase hydrolysate was hydrolysed significantly faster $(95 \cdot 4 \pm 5 \cdot 4$ mmol glucose $/ \mathrm{h} / 25 \mathrm{~cm}$ ) than the partial amylase hydrolysate $(67 \cdot 9 \pm 3 \cdot 0, \mathrm{p}<0 \cdot 01, \mathrm{n}=5$ ) (see Tables 1 and 2). The extent and rates of hydrolysis of the various fractions of the complete $\alpha$-amylase hydrolysate are shown in Table 3.

It should be noted that in all these experiments quantitation of the hydrolysis rates of the lower molecular weight fractions of both the partial and complete amylase hydrolysates of starch will be an underestimate because of the transitory additions to these fractions that occur consequent upon hydrolysis of the higher molecular weight fractions.

Nevertheless, both the extent and rate of hydrolysis of the G3 $(80 \cdot 1 \pm 1 \cdot 8 \%$ and $48 \cdot 7 \pm 1.9 \mathrm{mmol}$ glucose $/ \mathrm{h} / 25 \mathrm{~cm}$ ) fraction reflect efficient hydrolysis during perfusion, with both the extent $(p<0.01)$ and
Fig. 2. Complete amylase hydrolysate of starch. Typical tracings obtained by gel permeation chromatography of complete amylase hydrolysate of corn starch $(A)$ used in perfusion studies, and intestinal aspirates $(B)$ obtained during perfusion of human jejunum. Shown below tracing $A$ is glucose content of individual peaks, or groups of peaks, expressed as percentage of total glucose content of hydrolysate. Values are means \pm SEM of six separately prepared hydrolysates of corn starch.

* Arrows indicate the appearance during perfusion of $(1 \rightarrow 6)$ linked trisaccharides in $G 3$ fraction, and isomaltose in G2 fraction.
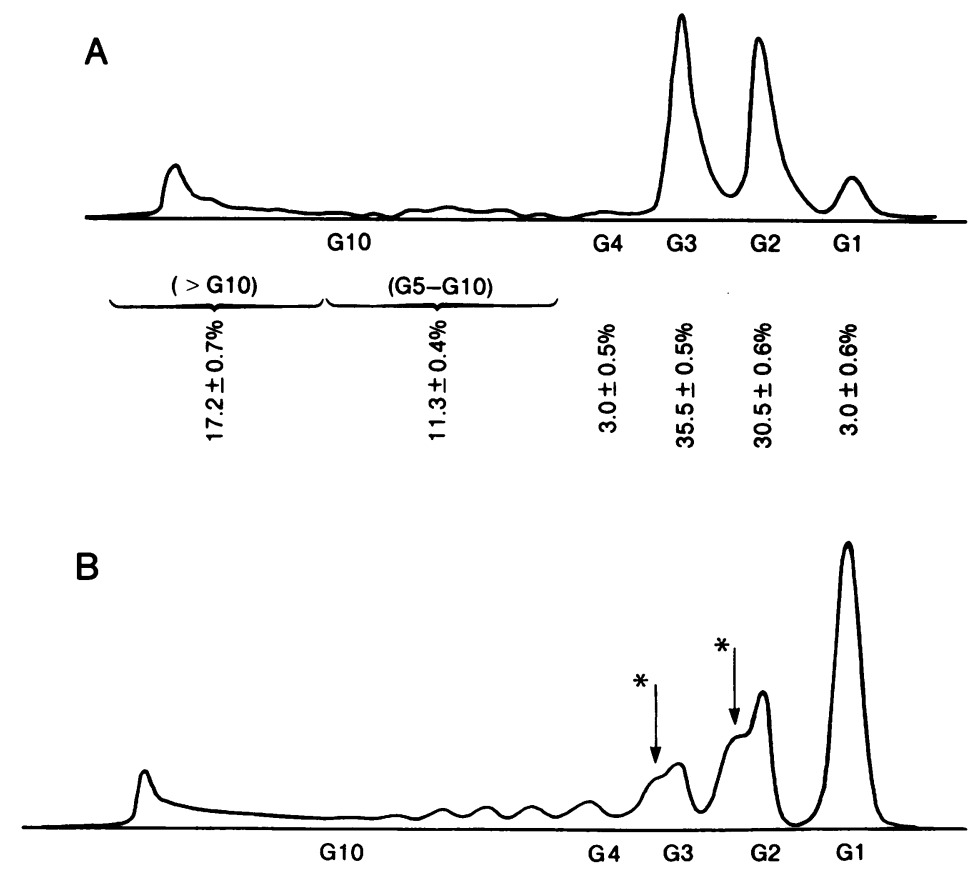
Table 3 In vivo hydrolysis of the complete amylase hydrolysate of starch during human jejunal perfusion

\begin{tabular}{|c|c|c|c|c|c|}
\hline & $(>G 10)^{*}$ fraction & $(G 4-G 10)^{*}$ fraction & G.3* fraction & $G 2^{*}$ fraction & All fractions \\
\hline $\begin{array}{l}\text { Extent of hydrolysis } \\
\% \text { hydrolysis of infused load } \\
\text { mean } \pm \text { SEM } \\
n=6\end{array}$ & $4(0 \cdot 6 \pm 3 \cdot 5$ & $17 \cdot 8 \pm 8 \cdot 3$ & 8()$\cdot 1 \pm 1 \cdot 8+$ & $63 \cdot 2 \pm 3 \cdot 6+$ & $59 \cdot 7 \pm 3 \cdot 0$ \\
\hline $\begin{array}{l}\text { Rate of hydrolysis } \\
\mathrm{mmol} \text { glucose } / \mathrm{h} / 25 \mathrm{~cm} \\
\mathrm{n}=6\end{array}$ & $11 \cdot 9 \pm 1 \cdot 3$ & $3 \cdot 2 \pm 1 \cdot 5$ & $48 \cdot 7 \pm 1 \cdot 9 \ddagger$ & $32 \cdot 7 \pm 2 \cdot 2 \ddagger$ & $95 \cdot 4 \pm 5 \cdot 4$ \\
\hline
\end{tabular}

${ }^{*}$ Denotes chain length of individual glucose polymer fractions. $\quad+p<0 \cdot(01 . \quad \neq p<0 \cdot(01$.

rate $(p<0.01)$ of hydrolysis of the G3 fraction exceeding that of the $\mathrm{G} 2$ fraction which was also hydrolysed with great efficiency (Table 3 ).

GLUCOSE ABSORPTION (MMOL/H/25 CM) FROM THE COMPLETE AMYLASE HYDROLYSATE OF STARCH In contrast with the results of the perfusions with the partial amylase hydrolysate, net glucose absorption occurred significantly faster from the complete $\alpha$-amylase hydrolysate $(81 \cdot 8 \pm 4 \cdot 8)$ than from the free glucose solution $(55 \cdot 8 \pm 4 \cdot 9, \mathrm{p}<0.001, \mathrm{n}=6$, Table 2). Net uptake of glucose also occurred significantly faster from the complete hydrolysate $(81 \cdot 1 \pm 5 \cdot 9)$ than the partial hydrolysate $(64 \cdot 2 \pm 3 \cdot 8$, $\mathrm{p}<0 \cdot 01, \mathrm{n}=5$ ).

\section{Discussion}

The aim of the present study was to determine whether the advantageous relationship which exists between maltose hydrolysis and subsequent glucose absorption $^{5-7}$ also occurs during the intestinal absorption of other glucose oligosaccharides. The partial $\alpha$-amylase hydrolysate of starch was chosen for the first part of the study because it was found by gel germeation chromatography to consist of a heterogeneous mixture of oligosaccharides of which half contained less than 11 glucose units. As the chromatograms suggested that these lower molecular weight oligosaccharides were predominantly linked by $(1 \rightarrow 4)$ glycosidic bonds, this group of sugars would be expected to have a high affinity for intestinal brush-border $\alpha$-glucoamylase according to in vitro data of Kelly and Alpers. ${ }^{16}$

In order to study brush-border hydrolysis, rather than luminal hydrolyses of these oligosaccharides, it was necessary to exclude amylase from the test segment with a proximal occlusive balloon. As the assay used to measure amylase activity was only capable of detecting activity of $37 \mathrm{IU} / \mathrm{l}$ or greater, we cannot exclude the possibility that luminal contents contained trace activities of this enzyme. In addition, low activities of exocrine pancreatic enzymes can be detected in homogenates of intestinal mucosa indicating adsorption of these enzymes to intestinal mucosa in vivo. ${ }^{17}$ It is probable therefore that residual $\alpha$-amylase adherent to the brush-border could have contributed to the mucosal hydrolysis of the partial hydrolysate of starch, particularly in the case of the relatively high molecular weight $(>$ G10) fractions. Despite this possibility, however, hydrolysis of the $(>\mathrm{G} 10)$ fraction was much slower than that of the lower molecular weight fractions.

This may be attributable in part to slower diffusion through the unstirred water layer ${ }^{18}$ of the larger molecular weight fractions in the absence of luminal hydrolysis to smaller saccharides, and partly to the lower affinity of brush-border $\alpha$-Dglucosidases (maltases) for the high molecular weight polysaccharides. ${ }^{16}$

The results showed that net glucose uptake from the partial amylase hydrolysate of starch was similar to that from free glucose. The marked differences, however, between the mucosal hydrolysis of the higher ( $>$ G10) and lower molecular weight fractions strongly suggested that the final net value for glucose uptake could only have been achieved if the more efficiently hydrolysed oligosaccharides (maltose, and oligosaccharides in the G3-G10 range) had conferred a kinetic advantage on glucose absorption, thereby counterbalancing the slower hydrolysis of the polysaccharides in the <G10 range.

The second series of experiments was performed to test this hypothesis. A preparation containing mainly low molecular weight oligosaccharides was prepared by complete amylolysis of the heterogenous glucose polymer mixture with $\alpha$-amylase. The perfusion results confirm that the low molecular weight oligosaccharides confer a kinetic advantage on glucose absorption, as glucose was absorbed faster from the complete amylase hydrolysate than from free glucose. The chromatograms of aspirated jejunal contents clearly show that it was not just maltose that was responsible for conferring the 
kinetic advantage, because maltotriose disappeared from the gut lumen even faster than maltose.

In contrast with the behaviour of $(1 \rightarrow 4)$ linked oligosaccharides in the complete $\alpha$-amylase hydrolysate, the G4-G10 fraction was hydrolysed poorly (Table 3$)$. The $(1 \rightarrow 6)$ linkages which predominate in this fraction are cleaved by the isomaltase subunit of the hybrid sucrase-isomaltase enzyme. The chromatograms of intestinal contents aspirated during perfusion of the complete amylase hydrolysate showed prominent peaks of $(1 \rightarrow 6)$ linked isomaltose and isomaltotriose (Fig. 2B), which were not apparent in the chromatograms of the infused material (Fig. 2A). This evidence points to the accumulation of smaller molecular residues containing $(1 \rightarrow 6)$ linkages and strongly suggests that hydrolysis of the $(1 \rightarrow 6)$ bond by isomaltase is rate limiting with respect to glucose transport.

Sucrose has also been shown to confer a kinetic advantage on glucose absorption in animals, ${ }^{19}$ but in man, experiments conducted by others, ${ }^{20}$ as well as our own preliminary unpublished data, have so far failed to show this. Further studies are in progress to resolve this paradox. On the basis of data presently available in man, it seems that an advantageous relationship exists between glucose transport sites and the brush-border enzymes responsible for hydrolysis of $(1 \rightarrow 4)$ linked glucose oligosaccharides. This is not so for $(1 \rightarrow 6)$ linked glucose oligosaccharides where hydrolysis is rate limiting. Confirmation of this hypothesis comes from our studies with maltotriose and an oligosaccharide mixture containing predominantly four to eight $(1 \rightarrow 4)$ linked glucose molecules for which a kinetic advantage with respect to glucose absorption has been shown. ${ }^{21}$

Various explanations for the kinetic advantage of maltose have been put forward and are equally applicable to the kinetic advantage shown for other oligosaccharides in the present study. Transport of unhydrolysed maltose,${ }^{5}$ hydrolase related transfer ${ }^{19}$ or proximity of the hydrolysis site to that of glucose transport ${ }^{22-24}$ have all been suggested. The finding that no significant glucose transport occurs during maltose perfusion in congenital glucose-galactose malabsorption, ${ }^{25}$ however, effectively renders the first two suggestions untenable. Moreover, there are no disaccharidases within the cytoplasmic compartment of the intestinal mucosal cell. ${ }^{2}$

The possibility that the various sodium contents of the perfused solutions may have had some bearing on the differences found in glucose absorption is unlikely as studies by Olsen and Ingelfinger ${ }^{26}$ found that glucose transport in vivo was not further influenced by luminal sodium ion concentrations higher than $5 \mathrm{mmol} / \mathrm{l}$.
The most probable explanation for the increased glucose absorption from maltose and other $(1 \rightarrow 4)$ linked oligosaccharides is that liberation of monosaccharide by brush-border enzymes achieves greater local concentrations at glucose transport sites than those achieved by random diffusion of free glucose through the unstirred water layer. ${ }^{23} 24$ $(1 \rightarrow 6)$ linked oligosaccharides are unlikely to contribute to this kinetic advantage because their hydrolysis is rate limiting for absorption.

Not all workers have shown faster glucose absorption from maltose than from free glucose,${ }^{34}$ but our data accord well with that of recently published human perfusion experiments. ${ }^{5-7}$ It is not clear why this discrepancy has arisen although the most probable explanation is variation in experimental technique.?

Extrapolation of data from a short segment of perfused jejunum to the intact gut should be undertaken with caution although it is reassuring that the complete amylase hydrolysate of starch used in the present studies closely resembles the profile of a starch meal as it reaches the proximal jejunum in man. ${ }^{27}$ The present experiments have all been performed at one concentration, but it is not yet known whether the kinetic advantage demonstrated for oligosaccharides is concentration dependent as has recently been shown with the related phenomenon of amino acid absorption from peptides. ${ }^{28}$ Moreover, similar gastric emptying rates of isocaloric carbohydrate test meals have been well documented $\mathrm{d}^{29}$ and oral tolerance tests have failed to show more rapid glucose absorption from a partial amylase hydrolysate of starch (Caloreen) than from free glucose. ${ }^{30}$

In conclusion, our data suggest that $(1 \rightarrow 4)$ but not $(1 \rightarrow 6)$ linked glucose oligosaccharides are absorbed from the jejunum more efficiently than free glucose at the concentrations studied. Thus the results of our study represent an interesting physiological phenomenon but it is not possible at present to determine the nutritional or clinical significance of our data with respect to the intact, diseased, or short gut.

The authors wish to thank Dr Alan Beavis and Michael Freeman for their assistance and also the volunteers without whom the project would not have been possible. We are also grateful to Mrs Kathleen Walker for secretarial assistance.

\section{References}

1 Gray GM. Carbohydrate digestion and absorption. Gastroenterology 1970; 58: 96-107. 
2 Silk DBA, Dawson AM. Intestinal absorption of carbohydrate and protein in man. International Review of Physiology: Gastrointestinal Physiology III 1979; 19: 151-204.

3 Gray GM, Santiago NA. Disaccharide absorption in normal and diseased human intestine. Gastroenterology 1966; 51: 489-98.

4 McMichael HB, Webb J, Dawson AM. The absorption of maltose and lactose in man. Clin Sci 1967; 33: $135-45$.

5 Cook GC. Comparison of absorption rates of glucose and maltose in man in vivo. Clin Sci 1973; 44: 425-8.

6 Sandle GI, Lobley RW, Holmes R. Effect of maltose on the absorption of glucose in the jejunum in man. [Abstract] Gut 1977; 18: A944.

7 Fairclough PD, Silk DBA, Webb JPW, Clark ML, Dawson AM. A reappraisal of osmotic evidence for intact peptide absorption. Clin Sci Mol Med 1977; 53: 241-8.

8 John M, Trenel G, Dellweg H. Quantitative chromatography of homologous glucose oligomers and other saccharides using polyacrylamide gel. J Chromatogr 1969; 42: 476-84.

9 Phillips SF, Summerskill WHJ. Occlusion of the jejunum for intestinal perfusion in man Gut 1966; 18: 990-3.

10 Sladen GE, Dawson AM. Further studies on the perfusion method for measuring intestinal absorption in man: effects of a proximal occlusive balloon and a mixing segment. Gut 1970; 11: 947-54.

11 Modigliani R, Rambaud JC, Bernier JJ. Validation of the use of a proximal occlusive balloon for measurement of intestinal absorption in man. Dig Diseases 1978; 23: 720-2.

12 Wingate DL, Sandberg RJ, Phillips SF. A comparison of stable and ${ }^{14} \mathrm{C}$ labelled polyethylene glycol as volume indicators in the human jejunum. Gut 1972; 13: 812-5.

13 Ceska M, Birath K, Brown B. New and rapid method for the clinical determination of $\alpha$-amylase activities in human serum and urine. Optimal conditions. Clin Chim Acta 1969; 26: 437-44.

14 Keppler D, Decker K. Glycogen, determination with amyloglucosidase. In: Bergmeyer HU, ed. Methods of enzymatic analysis. New York: Academic Press, 1974; 3: 1127-31.

15 Sladen GE, Dawson AM. An evaluation of perfusion techniques in the study of water and electrolyte absorption in man: the problem of endogenous secretions. Gut 1968; 9: 530-5.

16 Kelly JJ, Alpers DH. Properties of human intestinal glucamylase. Biochim Biophys Acta 1973; 315: 113-20.

17 Dahlquist A, Thomson DL. Separation and character- istics of two rat-intestinal amylases. Biochem $J$ 1963; 89: 272-7.

18 Wilson FA, Dietschy JM. The intestinal unstirred layer: its surface area and effect on active transport kinetics. Biochim Biophys Acta 1974; 363: 112-6.

19 Malathi P, Ramaswami WF, Caspary WF, Crane RK. Studies on the transport of glucose from disaccharides by hamster small intestine in vitro 1 . Evidence for a disaccharidase-related transport system. Biochim Biophys Acta 1973; 307: 613-26.

20 Gray GM, Ingelfinger JF. Intestinal absorption of sucrose in man: interrelation of hydrolysis and monosaccharide product absorption. J Clin Invest 1966; 45: 388-98.

21 Jones BJM, Brown BE, Silk DBA. Intestinal absorption of maltotriose and a maltopentose-hexose mixture in man. [Abstract]. Gut 1981; 22: A868.

22 Crane RK. Structural and functional organisation of an epithalid cell brush-border. In: Warren $\mathrm{KC}$, ed. Symposia of the International Society of Cell Biology. New York: Academic Press, 1966: 71-102.

23 Hanke DW, Harden DA, Evans JO, Fannin FF, Diedrich DF. The kinetic advantage for transport into hamster intestine of glucose generated from phlorizin by brush-border $\beta$-glucosidase. Biochim Biophys Acta 1980; 599: 652-63.

24 Warden DA, Fannin FF, Evans JO, Hanke DW, Diedrich DF. A hydrolase related transport system is not required to explain the intestinal uptake of glucose liberated from phlorizin. Biochim Biophys Acta 1980; 599: 664-72.

25 Fairclough PD, Clark ML, Dawson AM, Silk DBA, Milla P, Harries JT. Absorption of glucose and maltose in congenital glucose-galactose malabsorption. Pediatr Res 1978; 12: 1112-4.

26 Olsen WA, Ingelfinger FJ. The role of sodium in intestinal glucose absorption in man. J Clin Invest 1968; 47: $1133-42$.

27 Auricchio S, Pietra DD, Vegnente A. Studies on intestinal digestion of starch in man. II. Intestinal hydrolysis of amylopectin in infants and children. Pediatrics 1967; 38: 853-62.

28 Hegarty JE, Fairclough PD, Moriarty KJ, Kelly MJ, Clark ML. Effects of concentration on in vivo absorption of a peptide containing protein hydrolysate. Gut 1982; 23: 304-9.

29 Hunt JN. The site of receptors slowing gastric emptying in response to starch in test meals. $J$ Physiol 1960; 154: 270-6.

30 Wahlquist ML, Wilmshurst EG, Murton CR, Richardson EN. The effect of chain length on glucose absorption and the related response. Am J Clin Nutr 1978; 31: 1998-2001. 